\title{
PFAT5 stability assessment of Lipovenoes MCT in total nutrient admixtures
}

\author{
Shanshan Gao, Jing Fan, Xiuling Jia, Bangbang Li, Xiangcheng Li, Zongli Li, Jing Li \\ Department of Pharmacy, Affiliated Hospital of Qingdao University, Qingdao, China \\ Contributions: (I) Conception and design: S Gao, J Li; (II) Administrative support: J Li; (III) Provision of study materials or patients: S Gao, X Li; (IV) \\ Collection and assembly of data: S Gao, X Li; (V) Data analysis and interpretation: S Gao, X Li; (VI) Manuscript writing: All authors; (VII) Final \\ approval of manuscript: All authors. \\ Correspondence to: Jing Li. Chief Pharmacist, Postgraduate Tutor, Affiliated Hospital of Qingdao University, Qingdao 266003, China. \\ Email: lijing7112@126.com.
}

Background: The purpose of this study was to evaluate the effects of monovalent and divalent cations on the stability of a fat emulsion (Lipovenoes MCT) in total nutrient admixtures (TNAs) by testing the percentage of fat residing in globules $>5 \mu \mathrm{m}$ (PFAT5) values.

Methods: TNAs with different combinations of glucose (5\% and $10 \%)$, amino acids (3.35 and $4.5 \mathrm{~g} / 100 \mathrm{~mL}), \mathrm{Na}^{+} / \mathrm{K}^{+}(100 / 39 \mathrm{mmol} / \mathrm{L}), \mathrm{Mg}^{2+}$ (3.4 and $\left.2.7 \mathrm{mmol} / \mathrm{L}\right)$, and fat emulsion $(2.4 \%)$ were tested in triplicate at room temperature. The $\mathrm{pH}$, mean droplet size (MDS), and PFAT5 were assessed at 0, 6, 12, 24, 36, and $48 \mathrm{~h}$.

Results: In all seven groups, the TNA globule distribution was uniform, the $\mathrm{pH}$ value fluctuated in the range of 5.93-6.06, and the MDS met the limit of the United States Pharmacopeia (USP) within 48 h. The PFAT5 value of the control group 0 without electrolytes was the lowest; group 1 added monovalent ions of $139 \mathrm{mmol} / \mathrm{L}$ was significantly higher $(\mathrm{P}<0.05)$ but without exceed the USP limit after 48 h. Groups 2 and 3 added $\mathrm{Mg}^{2+} 3.4$ and $2.7 \mathrm{mmol} / \mathrm{L}$ respectively, based on group 1. Group 4 increased the amino acid concentration from $3.35 \%$ to $4.5 \%$ based on group 2, and group 5 reduced the glucose concentration from $10 \%$ to $5 \%$ based on group 4 . Group 6 removed monovalent ions and retained only $\mathrm{Mg}^{2+}$ based on group 5 . The PFAT5 values of group 2, 3, 4, and 5 exceeded the limit after $6 \mathrm{~h}$ and group 6 after $12 \mathrm{~h}$. There was no statistical difference between group 2 and $4(\mathrm{P}>0.05)$ or between group 4 and $5(\mathrm{P}>0.05)$.

Conclusions: When the concentration of glucose is $10-25 \%$ and the amino acid is $2.5-4.5 \%$, The addition of monovalent ions affects the stability of fat emulsion in TNAs, however when the concentrations of $\mathrm{Na}^{+}$ $\leq 100 \mathrm{mmol} / \mathrm{L}$ and $\mathrm{K}^{+} \leq 39 \mathrm{mmol} / \mathrm{L}$, the $\mathrm{PFAT}_{5}$ value will not exceed the USP limit within $24 \mathrm{~h} . \mathrm{Mg}^{2+}$ has a significant effect, the $\mathrm{PFAT}_{5}$ value will exceed the USP limit after $6 \mathrm{~h}$ when the concentration $\geq 2.7 \mathrm{mmol} / \mathrm{L}$, which may cause potential safety hazards.

Keywords: Total nutrient admixtures (TNAs); PFAT5; stability of Lipovenoes MCT; monovalent ions; magnesium ion

Submitted Sep 26, 2021. Accepted for publication Dec 15, 2021.

doi: 10.21037/apm-21-3353

View this article at: https://dx.doi.org/10.21037/apm-21-3353

\section{Introduction}

Patients transferred to an intensive care unit (ICU) are frequently malnourished because of their life-threatening diseases (1). A series of catabolic reactions in critically ill patients, such as the secretion of hormones, catecholamines, and proinflammatory cytokines, leads to proteolysis and muscle loss (up to $1 \mathrm{~kg} / \mathrm{day}$ ), as well as lipolysis and weight loss, which in turn lead to an increased death rate (2-4). Furthermore, patients with extensive burns, patients whose gastrointestinal function cannot recover within 5-7 days 
after major surgery, or patients with short bowel syndrome are unable to eat. They may have serious malnutrition and increased postoperative complications, which will increase mortality (5). For these reasons, proper nutritional supplementation for patients, such as with a total nutrient admixture (TNA), is vital for reducing postoperative complications and promoting recovery as recommended by the European Society for Clinical Nutrition and Metabolism (ESPEN) guidelines (6). The American Society for Parenteral and Enteral Nutrition (ASPEN) also recommends that TNAs be used when the patient cannot eat (3). Therefore, TNAs are widely used in many medical fields.

TNAs are liquid mixtures containing glucose, amino acids, fat emulsion, electrolytes, trace elements, and multivitamins (MV). They are intravenously infused through a vein (7). Fat emulsions have been a crucial component of TNAs for many years, serving as excellent carriers for essential fats and energy (8). The stability of fat emulsion determines the quality of the TNA. After adding the fat emulsion to a TNA, various factors may affect its stability, resulting in the oil droplets merging and increasing the particle sizes, which not only hinders the effective utilization of fatty acids but may also cause severe adverse reactions and damage to the patient's body. Parenteral nutrition (PN) preparations are listed as highalert medications by the Institute for Safe Medication Practices (ISMP), as their improper use can cause patient injury or death (9). Therefore, the stability of fat emulsion is the basis for the rational application of TNA. Given the broad application of TNAs, we believe it is very important to study the stability of fat emulsions under current liquid preparation practices. To date, due to the limitations caused by different manufacturers and different detection methods, studies on the stability of fat emulsion, have been carried out continuously The $\mathrm{pH}$ of a stable fat emulsion injection is between 6-9. Glucose injections $(\mathrm{pH} 3.2-6.5)$ can affect emulsion stability (10). When the $\mathrm{pH}$ is lower than 5.0, a fat emulsion becomes unstable (11). An amino acid injection can buffer the $\mathrm{pH}$ of a TNA (12). The concentration has been shown to be a sensitive determinant of fat emulsion stability in neonatal TNAs (13). Addition electrolytes to TNAs, especially divalent cations, will reduce stability. A divalent cation can damage the lipid-droplet surface charge and alter the repulsive force, rendering a fat emulsion unstable (14).

The Chinese Society of Parenteral and Enteral Nutrition (CSPEN) pointed out that the percentage of fat residing in globules $>5 \mu \mathrm{m}$ (PFAT5) can be effectively used to determine the stability of fat emulsion compared with mean droplet size (MDS) and the zeta potential (15). PFAT5 is the most accurate and effective validated measure of lipid stability (16). The United States Pharmacopeia (USP) Chapter 729 has stipulated that the percentage of fat residing in globules $>5 \mu \mathrm{m}$ (PFAT5) value cannot exceed $0.05 \%$ (17). More stability studies using PFAT5 as the crucial measure are needed to identify the actual limits of TNA (16). As the basic components of TNAs, electrolytes are necessary for patients every day, the effects of monovalent and divalent cations on the stability of a fat emulsion were measured by testing the PFAT5 values, MDS, and the $\mathrm{pH}$ values of TNAs containing these elements in different concentrations in this study.

We present the following article in accordance with the MDAR reporting checklist (available at https://dx.doi. org/10.21037/apm-21-3353).

\section{Methods}

\section{Preparation of the TNAs}

The following products were used for the preparation of the TNAs: $10 \%$ glucose injection (Huaren Pharmaceutical Co. Ltd., Qingdao, China), 50\% glucose injection (Fresenius Kabi SSPC, Wuxi, China), 20\% medium-and long-chain fat emulsion injection (C6-24), Lipovenoes MCT (Fresenius KabiSSPC, Wuxi, China), Compound amino acid injection (18AA-II), Novamin ${ }^{\circledR} 11.4 \%$ (Fresenius Kabi SSPC, Wuxi, China), $10 \%$ potassium chloride injection (Shanghai Shyndec Pharmaceutical Co. Ltd., Tianjin, China), 10\% concentrated sodium chloride injection (Sinopharm Rong sheng Pharmaceutical Co. Ltd., Jiaozuo, China), and 25\% magnesium sulfate injection (Tianjin King York Pharmaceutical Co. Ltd., Tianjin, China).

The specification indicated that the concentration of monovalent cations should be less than $139 \mathrm{mmol} / \mathrm{L}$, the concentration of $\mathrm{Mg}^{2+}$ should be less than $3.4 \mathrm{mmol} / \mathrm{L}$, and the human body's daily demand for Magnesium ion is $8-12 \mathrm{mmol}(15,18)$, The liquid volume of common TNA is calculated as $2.5-3 \mathrm{~L}$, So the minimum concentration of daily demand for $\mathrm{Mg}^{2+}$ is $2.7 \mathrm{mmol} / \mathrm{L}$. Seven groups of prescription TNA were designed according to the concentration requirements, as shown in Table 1. Group 0 was the control group, to which no cations were added. In group 1, 10\% concentrated sodium chloride injection and $10 \%$ potassium chloride injection were added, and the concentrations of $\mathrm{Na}^{+}$and $\mathrm{K}^{+}$were 100 and 
Table 1 Ingredients of total nutrient admixtures formulations studied

\begin{tabular}{lccccccc}
\hline & \multicolumn{5}{c}{ Formula/Group No. } \\
\cline { 2 - 7 } Prescription ingredient & 0 & 1 & 2 & 3 & 4 & 5 \\
\hline Glucose (\%) & 10 & 10 & 10 & 10 & 10 & 5 \\
Amino acids (g/100 mL) & 3.35 & 3.35 & 3.35 & 3.35 & 4.5 & 4.5 & 4.5 \\
Fat emulsion (\%) & 2.4 & 2.4 & 2.4 & 2.4 & 2.4 & 2.4 \\
$\mathrm{Na}^{+}(\mathrm{mmol} / \mathrm{L})$ & 0 & 100 & 100 & 100 & 100 & 100 \\
$\mathrm{~K}^{+}(\mathrm{mmol} / \mathrm{L})$ & 0 & 39 & 39 & 39 & 39 & 39 \\
$\mathrm{Mg}^{2+}(\mathrm{mmol} / \mathrm{L})$ & 0 & 0 & 3.4 & 2.7 & 3.4 & 3.4 \\
\hline
\end{tabular}

$39 \mathrm{mmol} / \mathrm{L}$. In groups 2 and 3, 25\% magnesium sulfate injection was added and the concentrations of $\mathrm{Mg}^{2+}$ were 3.4 and $2.7 \mathrm{mmol} / \mathrm{L}$, respectively, based on the design of group 1. Group 4 increased the amino acid concentration from $3.35 \%$ to $4.5 \%$ based on the design of group 2 . Group 5 reduced the glucose concentration from $10 \%$ to $5 \%$ based on the design of group 4. Group 6 removed monovalent cations and retained only $\mathrm{Mg}^{2+} 3.4 \mathrm{mmol} / \mathrm{L}$ based on the design of group 5 . All samples were configured by professionally trained pharmaceutical personnel in accordance with the aseptic operation procedures for a 100 -grade cleanliness biosafety cabinet. The final total volume of each sample was $85 \mathrm{~mL}$. The TNAs were stored at room temperature for $0,6,12,24 \mathrm{~h}$, and refrigerated (2-8 degrees) for 36 and $48 \mathrm{~h}$, respectively and were tested in triplicate.

\section{$p H$}

The $\mathrm{pH}$ of the admixtures was determined using a controller (Mettler Toledo Instrument Co. Ltd., Switzerland).

\section{MDS and PFATS}

The MDS and the PFAT5 level of the TNAs were assessed respectively following Method I and II of USP Chapter729. Approximately $5 \mathrm{~mL}$ of each TNA sample was collected under sterile conditions. Then, the sample was gently swirled and injected directly into an AccuSizer 780/APS (Entegris, Billerica, MA, USA) equipped with an automatic dilution device and single-particle optical sensing (SPOS) technology for light extinction (LE). The samples were tested at 0,6 , 12, 24, 36 and $48 \mathrm{~h}$. The particle count time of each sample was $180 \mathrm{~s}$. If the average intensity-weighted MDS result was less than $500 \mathrm{~nm}$, the emulsion sample passed the limits of Method I. Data regarding the PFAT5 were extracted by summing and volume-weighting the fat globule sizes from each channel. If the volume-weighted PFAT5 was less than $0.05 \%$, the sample passed the limit of Method II.

\section{Statistical analysis}

All data are presented as means and standard deviations $(\bar{x} \pm \mathrm{s})$. The PFAT5 of each TNA prescription group was statistically analyzed by SPSS 19.0 software. Analysis of variance (ANOVA) was conducted based on the TNA formula and/or time as the independent variables and the PFAT5 as the dependent variables. For significant differences detected by ANOVA, Student's $t$-tests were performed for pairwise comparisons.

\section{Results}

\section{Appearance analysis}

The distribution of the TNA in each group was uniform within $48 \mathrm{~h}$, without discoloration, flocculation, sedimentation, and stratification, and showed a white emulsion with good fluidity.

\section{$p H$}

The $\mathrm{pH}$ value of the TNA infusions in all seven groups fluctuated within a range of 5.93-6.06 over $48 \mathrm{~h}$, as shown in Figure 1. Compared with group 4, the $\mathrm{pH}$ value of group 5 increased $0.09 \pm 0.02$.

\section{MDS}

As shown in Table 2, the MDS of the TNA infusions in all 
seven groups met the globule size limits for Method I of USP Chapter 729.

\section{PFAT5}

The PFAT5 results for the TNAs of all seven groups are shown in Table 2, with partial results shown in Figure 2. The differences in the PFAT5 levels measured $(n=21)$ in the TNAs were significant $(\mathrm{P}<0.05)$ with a 2 -way ANOVA based on formula and time as the independent variables. The PFAT5 value of the control group $0(n=3)$ with no added cations was significantly lower than other groups. The PFAT5 value of group $1(n=3)$, which contained monovalent cations, was significantly higher than that of group 0 , with a statistical difference of $\mathrm{P}<0.05$ but did not exceed the USP limit (PFAT5 $<0.05 \%$ ). The PFAT5 value of group $2(n=3)$ and group $3(n=3)$ exceeded the USP limit

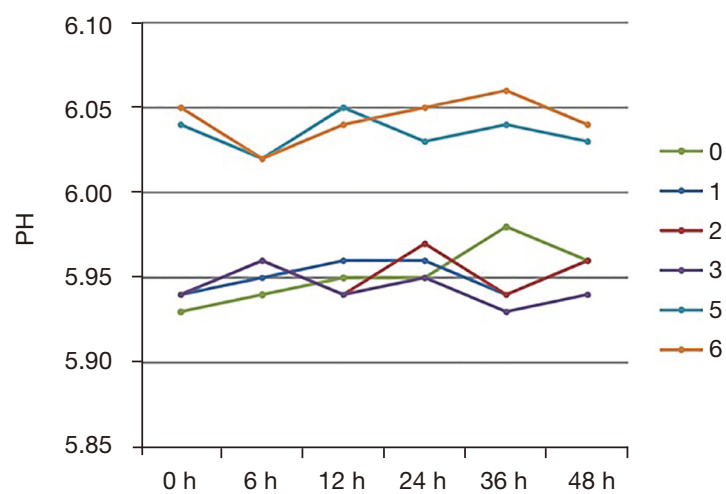

Figure 1 The pH-t curve of the seven TNA groups. TNA, total nutrient admixture.
(PFAT $5>0.05 \%$ ) after $6 \mathrm{~h}$. The divalent cations in the group 2 TNA were reduced in the group 3 TNA $(n=3)$ to meet the daily requirements of the human body, and the PFAT5 value of group 3 exceeded the USP limit (PFAT5 $>0.05 \%)$ after $6 \mathrm{~h}$. The group 4 TNA ( $=3)$ was obtained by increasing the amino acid content based on the design of the group 2 TNA, and there was no statistical difference between these two groups $(\mathrm{P}=0.499)$. The group 5 TNA $(\mathrm{n}=3)$ was obtained by reducing the glucose concentration based on the design of the group 4 TNA, and there was no statistical difference between these two groups $(\mathrm{P}=0.800)$. The monovalent cations in the group 5 TNA were removed to obtain the group 6 TNA $(n=3)$. However, the PFAT5, in this case, was found to exceed the USP limit (PFAT5 $>0.05 \%$ ) after $12 \mathrm{~h}$.

\section{Discussion}

Three main additives affected the stability of the fat emulsions, the first of which was the $\mathrm{pH}$ value. With lower $\mathrm{pH}$ values, the surface charge between the droplets was reduced, and the negative potential was also reduced, weakening the repulsion force between the droplets and causing the fat emulsion particles to agglomerate, thus reducing the fat emulsion stability. Glucose has a low $\mathrm{pH}$ (3.2-5.5) (10), and the addition of glucose had the effect of lowering the $\mathrm{pH}$ value. The $\mathrm{pH}$ value increased $0.09 \pm 0.02$ when the glucose concentration of the sample decreased from $10 \%$ (group 4 ) to $5 \%$ (group 5). With a fixed glucose concentration, changing the concentration of amino acids and electrolytes within a certain range had little effect on the $\mathrm{pH}$ value of the TNAs. Furthermore, over the

Table 2 Change of fat globule size in different TNAs

\begin{tabular}{|c|c|c|c|c|c|c|c|c|c|c|c|c|}
\hline $\begin{array}{l}\text { TNA } \\
\text { No. }\end{array}$ & \multicolumn{6}{|c|}{ Mean droplet size (MDS) (nm) } & \multicolumn{6}{|c|}{ The percentage of fat residing in globules $>5 \mu \mathrm{m}$ (PFAT5) $\left(\times 10^{-2} \%\right)$} \\
\hline 0 & $281 \pm 5$ & $286 \pm 2$ & $294 \pm 8$ & $295 \pm 6$ & $301 \pm 12$ & $287 \pm 7$ & $2.02 \pm 0.04$ & $2.13 \pm 0.06$ & $1.99 \pm 0.04$ & $2.23 \pm 0.16$ & $2.33 \pm 0.16$ & $2.13 \pm 0.12$ \\
\hline 1 & $289 \pm 6$ & $309 \pm 8$ & $307 \pm 5$ & $301 \pm 14$ & $299 \pm 9$ & $301 \pm 3$ & $3.25 \pm 0.06$ & $3.85 \pm 0.14$ & $3.31 \pm 0.12$ & $3.32 \pm 0.12$ & $3.68 \pm 0.24$ & $3.37 \pm 0.28$ \\
\hline 2 & $288 \pm 2$ & $313 \pm 6$ & $339 \pm 7$ & $375 \pm 12$ & $372 \pm 7$ & $383 \pm 18$ & $3.24 \pm 0.03$ & $7.31 \pm 0.76$ & $13.16 \pm 1.77$ & $21.21 \pm 175$ & $29.77 \pm 1.16$ & $36.57 \pm 2.81$ \\
\hline 4 & $286 \pm 10$ & $309 \pm 6$ & $331 \pm 11$ & $362 \pm 11$ & $368 \pm 14$ & $382 \pm 2$ & $3.16 \pm 0.07$ & $7.33 \pm 0.12$ & $12.57 \pm 0.30$ & $21.20 \pm 1.15$ & $30.12 \pm 1.58$ & $36.47 \pm 2.63$ \\
\hline 5 & $288 \pm 8$ & $310 \pm 8$ & $342 \pm 9$ & $370 \pm 14$ & $375 \pm 10$ & $383 \pm 4$ & $3.24 \pm 0.11$ & $7.35 \pm 0.16$ & $12.54 \pm 0.28$ & $23.32 \pm 1.67$ & $31.04 \pm 1.06$ & $36.38 \pm 2.48$ \\
\hline 6 & $288 \pm 14$ & $307 \pm 8$ & $329 \pm 4$ & $355 \pm 10$ & $357 \pm 11$ & $361 \pm 4$ & $3.26 \pm 0.07$ & $4.57 \pm 0.32$ & $5.94 \pm 0.23$ & $8.42 \pm 091$ & $9.62 \pm 1.42$ & $13.69 \pm 1.03$ \\
\hline
\end{tabular}

TNA, total nutrient admixture; MDS, mean droplet size; PFAT5, percentage of fat globules $>5 \mu \mathrm{m}$; TNAs, total nutrient admixtures. 

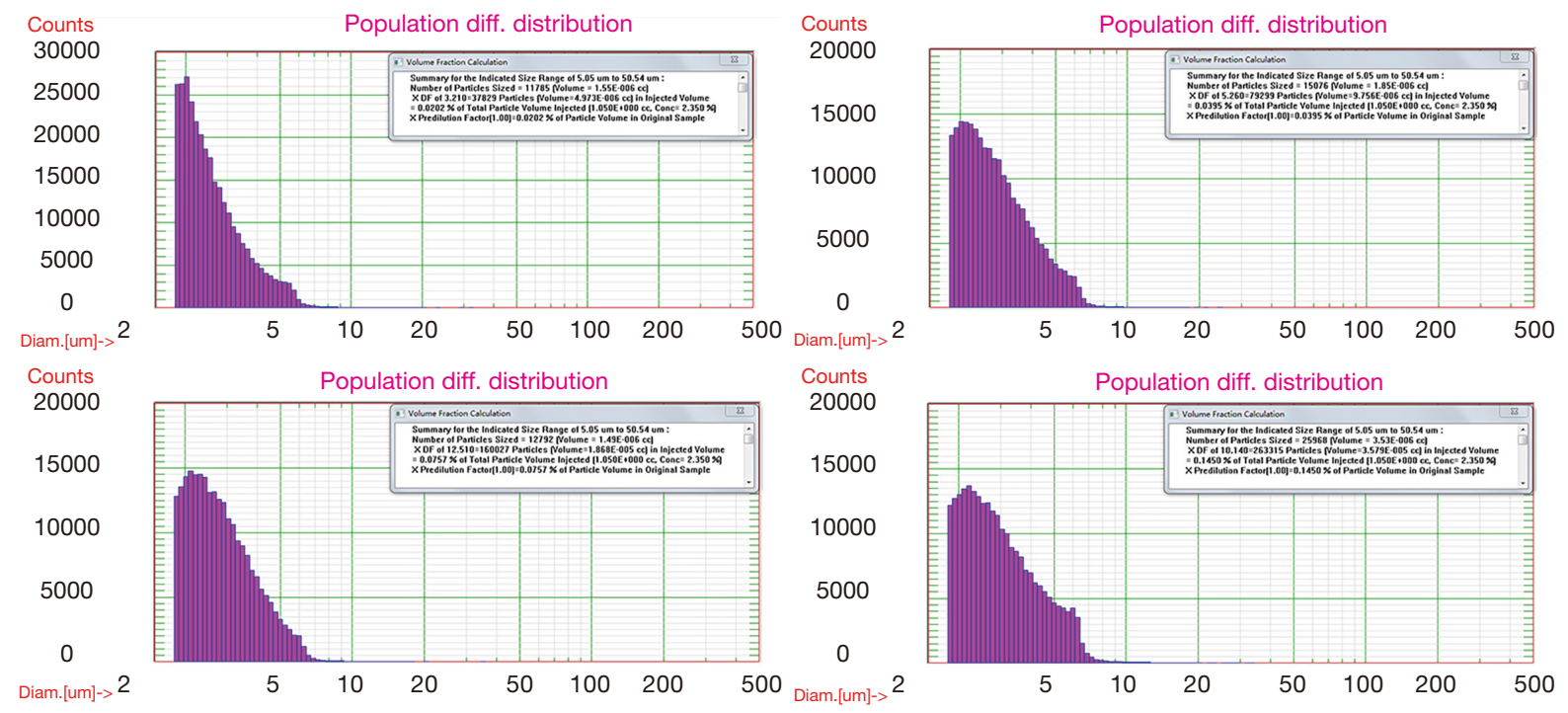

Figure 2 Partial PFAT5 results for TNAs in group 0 (0 h), group 1 (6 h), group $2(6 \mathrm{~h})$ and group 2 (12 h). PFAT5, percentage of fat globules $>5 \mu \mathrm{m}$; TNAs, total nutrient admixtures.

course of $48 \mathrm{~h}$, there was no statistical difference in the $\mathrm{pH}$ value for the TNAs $(\mathrm{P}>0.05)$. It can be seen that glucose, amino acids, and electrolytes have no significant effect on the stability of fat emulsion by changing the $\mathrm{pH}$ value of parenteral nutrition solution.

Secondly, amino acids can also affect the stability of fat emulsions as they can enhance the electrostatic barrier and buffer force, protect the electrolyte complex, and reduce the interaction of lipid particles. With an amino acid concentration of between $2.5 \%$ and $8.5 \%$, the stability of the fat emulsion in a TNA can be maintained (19). This is because the addition of amino acids worsens the conductivity but increases the viscosity and buffer capacity of the continuous phase (14). There was no significant difference in emulsion stability with different types of amino acid injection (20).

Thirdly, fat emulsions are a type of sol liquid. Too many electrolytes will cause instability in the sol system fat emulsion. The addition of a cation can change the repulsion force. Divalent cations, in particular, have a strong tendency to neutralize the negative charge on the surface of the fat emulsion drops, which affects stability as it makes it easier for the drops to aggregate. If the cation concentration is too high, a fat emulsion can easily become unstable, forming large oil droplets and demulsifying. The stability of the fat emulsion in a TNA largely depends on the concentration of cations in the mixture. The demulsification effect of divalentions in a TNA is not more serious than in a fat emulsion, but it is complex and can be unpredictable. Electrolytes are necessary for patients and are a primary component of PN. Therefore, it is crucial to study their effect on the stability of a fat emulsion. To date, there has been no international agreement about cation concentration limits in TNAs. For example, according to the current standard $(21,22)$, monovalent cation concentrations should be less than $150 \mathrm{mmol} / \mathrm{L}$, and divalent cation concentrations should be less than $10 \mathrm{mmol} / \mathrm{L}$, while according to the American Society of Health's Handbook on injectable drugs (23), the stability of a TNA can only be guaranteed when the concentration of $\mathrm{Mg}^{2+}$ is less than $3.4 \mathrm{mmol} / \mathrm{L}$, and the concentration of $\mathrm{Ca}^{2+}$ is less than $1.7 \mathrm{mmol} / \mathrm{L}$. The standard $(24,25)$ for $\mathrm{PN}$ in China stipulates that a concentration of divalent cations in the range of 5-8 mmol/L does not affect the stability of a TNA. Because there is no uniform cation limit requirement, the pharmaceutical standards in TNA testing differ, which is very detrimental to patient safety in the clinical application of TNAs.

In this study, the effect of cations on the stability of fat emulsion was investigated based on the PFAT5 value. No cation was added to group 0 as the control group. The group $1 \mathrm{TNA}$ added $\mathrm{Na}^{+} 100 \mathrm{mmol} / \mathrm{L}$ and $\mathrm{K}^{+} 39 \mathrm{mmol} / \mathrm{L}$ based on the design of group 0 according to the maximum cation provided by the specification (18) to study the effect of high concentration monovalent cations on the stability of fat emulsion. Results showed that the PFAT5 value of 
group 1 increased significantly compared with group 0 , with a statistical difference of $(\mathrm{P}<0.05)$. PFAT5 values did not change significantly over the course of the $48 \mathrm{~h}(\mathrm{P}>0.05)$. Despite the significant increase, the PFAT5 value of group 1 did not exceed the USP limit. These results show that a high concentration of monovalent cations has a significant impact on the stability of fat emulsion but will not lead to its PFAT5 exceeding the standard. Therefore, when the concentration of $\mathrm{Na}^{+}$and $\mathrm{K}^{+}$does not exceed 100 and $39 \mathrm{mmol} / \mathrm{L}$, respectively, monovalent cations can be added according to the needs of patients. Based on the design of the group 1 TNA, the prescription of group 2 was obtained by adding a high concentration of $\mathrm{Mg}^{2+}$, and the concentration was $3.4 \mathrm{mmol}$. Results showed that the group 2 TNA exceeded the USP limit after 6 hours. The daily magnesium requirement of the human body is $8-12 \mathrm{mmol}$. If the amount of parenteral nutrition liquid prescribed is $3,000 \mathrm{~mL}$, the concentration of $\mathrm{Mg}^{2+}$ in a TNA must not be less than $2.7 \mathrm{mmol} / \mathrm{L}$ to meet that requirement. Accordingly, the TNA for group 3 was obtained by reducing the concentration of $\mathrm{Mg}^{2+}$ to $2.7 \mathrm{mmol} / \mathrm{L}$. Results showed that the group 3 TNA exceeded the USP limit after 6 hours. The stability of the fat emulsion did not meet the clinical requirements. As a higher amino acid concentration increases the buffering capacity and is beneficial to the stability of fat emulsion, the prescription of group 4 was obtained by adding amino acid concentration to $4.5 \%$ based on the design of the group 2 TNA. The PFAT5 results showed no statistical difference in the PFAT5 values of groups 2 and $4(\mathrm{P}=0.499)$. The prescription of group 5 was obtained by reducing the glucose levels of the group 4 TNA to raise the $\mathrm{pH}$ level to over 6.0. There was no statistical difference between the two groups $(\mathrm{P}=0.800)$. These results suggest that increasing the amino acid concentration and reducing the glucose concentration under these conditions does not change the effect of $\mathrm{Mg}^{2+}$ on the stability of a fat emulsion. The prescription of group 6 was obtained by withholding the monovalent cations used in the group 5 TNA. Results showed that the group 6 TNA exceeded the USP limit after $12 \mathrm{~h}$. When the concentration of $\mathrm{Mg}^{2+}$ was $3.4 \mathrm{mmol} / \mathrm{L}$, the stability of the fat emulsion could not meet the requirements for a clinical TNA infusion over $24 \mathrm{~h}$, even if monovalent cations were not added.

Lipovenoes MCT (Fresenius Kabi SSPC, Wuxi, China) holds a $62 \%$ market share of the fat emulsion market in China. For this reason, we selected Lipovenoes MCT for this study and examined the stability of Lipovenoes MCT with the addition of cations to provide a guide for the clinical application of fat emulsions in China. The results show that the addition of cations significantly affects the stability of the fat emulsion, which in turn significantly increases its PFAT5 value. The addition of $\mathrm{Mg}^{2+}$ will cause the PFAT5 value of the fat emulsion to exceed the USP limit. Reducing the concentration of $\mathrm{Mg}^{2+}$ to meet the body's minimum requirement cannot guarantee that the stability of the fat emulsion will meet the clinical requirements for a TNA. Therefore, the addition of magnesium ions to TNAs may cause potential safety hazards. Pharmaceutical staff should pay special attention to the concentration of electrolytes when reviewing medical orders.

Finally, the composition of TNAs is complex. The experimental designed formula abandons the interaction and influence of vitamins and trace elements to make the experiment more concise and clearer, but there may be some limitations. At the same time, the influence of $\mathrm{Ca}^{2+}$ was not detected in this test, and further experimental research will be carried out in the follow-up.

\section{Acknowledgments}

Funding: None.

\section{Footnote}

Reporting Checklist: The authors have completed the MDAR reporting checklist. Available at https://dx.doi. org/10.21037/apm-21-3353

Data Sharing Statement: Available at https://dx.doi. org/10.21037/apm-21-3353

Conflicts of Interest: All authors have completed the ICMJE uniform disclosure form (available at https://dx.doi. org/10.21037/apm-21-3353). The authors have no conflicts of interest to declare.

Ethical Statement: The authors are accountable for all aspects of the work in ensuring that questions related to the accuracy or integrity of any part of the work are appropriately investigated and resolved.

Open Access Statement: This is an Open Access article distributed in accordance with the Creative Commons Attribution-NonCommercial-NoDerivs 4.0 International License (CC BY-NC-ND 4.0), which permits the noncommercial replication and distribution of the article with 
the strict proviso that no changes or edits are made and the original work is properly cited (including links to both the formal publication through the relevant DOI and the license). See: https://creativecommons.org/licenses/by-nc-nd/4.0/.

\section{References}

1. Tomczak S, Stawny M, Dettlaff K, et al. Physicochemical Compatibility and Stability of Linezolid with Parenteral Nutrition. Molecules 2019;24:1242.

2. Vanhorebeek I, Van den Berghe G. Hormonal and metabolic strategies to attenuate catabolism in critically ill patients. Curr Opin Pharmacol 2004;4:621-8.

3. Singer P, Blaser AR, Berger MM, et al. ESPEN guideline on clinical nutrition in the intensive care unit. Clin Nutr 2019;38:48-79.

4. Puthucheary ZA, Rawal J, McPhail M, et al. Acute skeletal muscle wasting in critical illness. JAMA 2013;310:1591600.

5. Nomura E, Lee SW, Kawai M, et al. Comparison between early enteral feeding with a transnasal tube and parenteral nutrition after total gastrectomy for gastric cancer. Hepatogastroenterology 2015;62:536-9.

6. Weimann A, Braga M, Carli F, et al. ESPEN guideline: Clinical nutrition in surgery. Clin Nutr 2017;36:623-50.

7. Kuwahara T, Kaneda S, Shimono K, et al. Effects of fat emulsion and multivitamins on the growth of microorganisms in peripheral parenteral nutrition solutions. Int J Med Sci 2013;10:1079-84.

8. Gonyon T, Patel P, Owen H, et al. Physicochemical stability of lipid injectable emulsions: correlating changes in large globule distributions with phase separation behavior. Int J Pharm 2007;343:208-19.

9. Insititute for Safe Medication Practices. ISMP list of highalert medications in long-term care (LTC) settings. (201908-30) [2019-12-01]. Available online: https://www.ismp. org/recommendations/high-alert-medications-long-termcare-list

10. Boullata JI, Gilbert K, Sacks G, et al. A.S.P.E.N. clinical guidelines: parenteral nutrition ordering, order review, compounding, labeling, and dispensing. JPEN J Parenter Enteral Nutr 2014;38:334-77.

11. Singleton WS, Gray MS, Brown ML, et al. Chromatographically homogeneous lecithin from egg phospholipids. J Am Oil Chem Soc 1965;42:53-6.

12. Knutsen CV, Epps DR, McCormick DC, et al. Total nutrient admixture guidelines. Drug Intell Clin Pharm
1984;18:253-4.

13. Driscoll DF, Silvestri AP, Bistrian BR. Stability of MCT/ LCT-based total nutrient admixtures for neonatal use over 30 hours at room temperature: applying pharmacopeial standards. JPEN J Parenter Enteral Nutr 2010;34:305-12.

14. Télessy IG, Balogh J, Szabó B, et al. Kinetic stability of all-in-one parenteral nutrition admixtures in the presence of high dose $\mathrm{Ca} 2+$ additive under clinical application circumstances. Nutr J 2012;11:32.

15. CSPEN Pharmaceutical cooperation group. To standardize the preparation of parenteral nutrition solution. Chinese Journal of Clinical Nutrition 2018,26:72-84.

16. Klang MG. PFAT5 and the Evolution of Lipid Admixture Stability. JPEN J Parenter Enteral Nutr 2015;39:67S-71S.

17. USP. Globule size distribution in lipid injectable emulsions.; p. 567-610.

18. Consensus on clinical pharmacy of parenteral nutrition (Second Edition). Pharmacy Today 2017;27:289-303.

19. Bullock L, Fitzgerald JF, Walter WV. Emulsion stability in total nutrient admixtures containing a pediatric amino acid formulation. JPEN J Parenter Enteral Nutr 1992;16:64-8.

20. Barat AC, Harrie K, Jacob M, et al. Effect of amino acid solutions on total nutrient admixture stability. JPEN J Parenter Enteral Nutr 1987;11:384-8.

21. Driscoll DF, Bhargava HN, Li L, et al. Physicochemical stability of total nutrient admixtures. Am J Health Syst Pharm 1995;52:623-34.

22. Allen L V. Remington: The Science and Practice of Pharmacy. 22nd ed. Philadelphia: Pharmaceutical Press, 2014: 2267-2268

23. Trissel LA. Handbook on injectable drugs.14th ed. Bethesda, MD: American Society of Health-System Pharmacists, 2007: 82-92.

24. Li N, Yu J, Cai W. Clinical parenteral and enteral nutrition support therapeutics. Beijing: China Medical Electronic Audio-Visual Publishing Press, 2012: 236-240.

25. Chinese Medical Association Clinical technical operation specification parenteral and enteral nutrition. Beijing: People's Military Medical Press, 2008: 44.

(English Language Editors: L. Roberts and D. Fitzgerald)

Cite this article as: Gao S, Fan J, Jia X, Li B, Li X, Li Z, Li J. PFAT5 stability assessment of Lipovenoes MCT in total nutrient admixtures. Ann Palliat Med 2021;10(12):12244-12250. doi: 10.21037/apm-21-3353 